\title{
Apuntes sobre la categoría género desde una lectura antropológica
}

\begin{abstract}
Edgar Lara López ${ }^{1}$
Constantemente se escucha hablar de género, de su importancia en la incorporación en las ciencias, en la política y en el análisis de la realidad socioeconómica, así como también de desigualdades, estereotipos y roles de género, etc. Pero ¿qué entendemos por género?, ¿género es lo mismo que sexo y feminismo?, ¿cómo la antropología ha contribuido a la configuración de la categoría género?, ¿lo masculino y lo femenino es lo mismo en todas las sociedad?; este artículo tiene como objetivo exponer de manera sucinta las respuestas a las preguntas antes planteadas.
\end{abstract}

It is frequent to hear talks about gender, about its importance in science, in politics, and in the socioeconomic analysis, as well as about its inequalities, stereotypes, gender roles, etc. But, what can be understood by gender? Is gender the same as sex and feminism? How has the field of anthropology contributed to the configuration of the category of gender? Is male and female the same in all societies?. This article aims to briefly provide answers to all the questions above.

\section{Introducción}

Desde el surgimiento del feminismo, la antropología ha jugado un papel importante en el desarrollo de la categoría género; el estudio del ser humano en el contexto de su cultura y cómo éste se representa o se construye en el espacio social ha dado lugar a comprender que las diferencias entre hombres y mujeres en el campo político, social y económico están determinadas por un simbolismo sociocultural, que suele traducirse en relaciones desiguales de género.

El interés de la antropología por el estudio de la conducta de hombres y mujeres en relación a elementos socioculturales y biológicos sentó las bases para el surgimiento del género. En ese sentido, esta nota tiene como propósito el desarrollo conceptual de la categoría género desde una lectura antropológica, así como un sucinto marco teórico, tomando como base el libro de la doctora Aurelia Martín Casares Antropología del género: cultura mitos y estereotipos sexuales. Esta obra es un importante aporte al pensamiento feminista y a los estudios de género, ya que expone los principales hallazgos de las investigaciones antropologicas desde una perspectiva de género, la recuperación de los

1. Profesor de Etica de la Economía, en la Universidad Don Bosco. 
trabajos etnográficos realizados por las antropólogas, desarrolla todo un marco conceptual útil para incorporación de la categoría de género en otras disciplinas y plantea las actuales área temáticas de investigación en la materia.

Estos apuntes se han limitado a sistematizar, exponer y comentar los aportes expuestos en el libro de Martín Casares relacionados al desarrollo y definición de categoría género, y a cómo la antropología evidencia que las construcciones identitarias, roles y estereotipos de géneros no son de carácter universal, sino que varían de una sociedad a otra, así como también de un contexto histórico a otro. También, en la elaboración de este trabajo se han tomado en cuenta otras lectura complementarias que se identifican en la bibliografía, así como los conocimientos adquiridos y expuestos en el modulo sobre Introducción al pensamiento feminista y a la historia de las mujeres del máster sobre Género, Identidad y Ciudadanía de la Universidad de Huelva.

Para exponer el desarrollo de la categoría género desde una visión antropológica, este trabajo se ha estructurado en tres partes; la primera hace un breve esbozo sobre el feminismo y sus corrientes, ya que ha sido el feminismo el precursor de dicha categoría; la segunda, expone el marco conceptual/teórico del género: evolución, elementos e instancias, así como conceptos claves relacionados al mismo; la tercera, expone los aportes de la antropología en la construcción de los géneros (especialmente el masculino y femenino) y en la desmitificación de la universalidad de los estereotipos y roles de género presentes en la sociedad occidental; y por último algunas consideraciones finales.

Finalmente, estos apuntes han sido elaborados en mi calidad de becario de MAEC-AECID y organizado para contribuir como texto de apoyo introductorio de las estudiantes del Diplomado en Género y Economía organizado por la Organización de Mujeres Salvadoreñas por la Paz (ORMUSA) y la Universidad de El Salvador. Así como también, para la población estudiantil de la cátedra Etica de la economía de la Universidad Don Bosco, con quienes en los últimos años he expuesto de manera exploratoria la categoría género en el análisis del mercado de trabajo salvadoreño y para fomentar una mayor conciencia en el estudiantado sobre el estado de las desigualdades sociales, económicas y políticas entre hombres y mujeres.

\section{Feminismo}

Antes de proceder a definir la categoría género es importante hacer un esbozo sobre el feminismo, ya que han sido las feministas y los estudios sobre la mujer quienes han impulsado y desarrollado la perspectiva y categoría de género para el análisis de las ciencias, así como para el estudio de la sociedad misma.

Victoria Sau en el Diccionario Ideológico Feminista expone que el feminismo es "un movimiento social y político que se inicia formalmente a finales del siglo XVIII - 
aunque sin adoptar todavía esta denominación- y que supone la toma de conciencia de las mujeres como grupo o colectivo humano, de la opresión, dominación, y explotación de que han sido y son objeto por parte del colectivo de varones en el seno del patriarcado bajo sus distintas fases históricas de modelo de producción, lo cual las mueve a la acción para la liberación de su sexo con todas las transformaciones de la sociedad que aquella requiera".

Como movimiento, ha estado integrado por un conjunto de pensadoras (declaradas o no feministas) que han impregnado a las reivindicaciones feministas consistencia y rigurosidad académica y científica, y han contribuido al desarrollo de un pensamiento feminista. En el área filosófica se destacan: Poulain de la Barre, Olympe de Gouges, Mary Wollstonecraft, Cady Stanton, Simone de Beauvoir, Luce Irigaray, Kate Millett, Judith Butler, Celia Amorós, Amelia Valcár entre otras, quienes han desarrollado todo un marco conceptual y teórico para los estudios filosóficos y de género.

Es importante destacar que no hay una sola forma de hacer feminismo, éste está integrado por varias corrientes que surgen como respuesta e interpretaciones de las condiciones que las mujeres se enfrentan en la sociedad o de los espacios en los cuales están insertadas. El cuadro 1 procura exponer de manera sucinta las diferentes corrientes del feminismo, la cuales no son excluyentes entre sí, sino que expresan el carácter pluralista y multidisciplinario del mismo.

Como expone Cuder el feminismo no es una corriente que induzca al odio hacia los hombres o una especia de misandria, su propósito reside en la búsqueda de la igualdad entre los géneros, la igualdad entre hombres y mujeres (Cuder, 2002)

Por otra parte, el desarrollo del movimiento y pensamiento feminista ha impactado en las ciencias así como en la formulación de las políticas públicas. Así cada vez es más evidente como en el marco de las ciencias y las investigaciones está presente el análisis de las desigualdades de género; por ejemplo Martín retomando a Britt-Marie Thurén indica que "la antropología y el movimiento feminista se necesitan mutuamente porque si el feminismo quiere ser eficaz en su lucha política precisa informaciones que sólo la antropología puede proporcionar y, al mismo tiempo si la antropología quiere ser completa tiene que reconocer que toda las relaciones de poder, sin cerrar los ojos ante una de las asimetrías más frecuentes, el desequilibrio de recursos entre mujeres y hombres" (Martín, 2006: 29-30). Y en el campo de la política y formulación de la legislación las reivindicaciones feministas han contribuido ampliamente al avance de las igualdades civiles entre mujeres y hombres.

2. Mujeres en Red: el periódico feminista. Qué es el feminsmo. http://www.mujeresenred.net/spip. php?article1308 Consultado el 27 de enero de 2010. 
Uno de los grandes aportes del feminismo ha sido cuestionar el determinismo biológico como fuente de desigualdad entre mujeres y hombres; planteando así que son las construcciones socioculturales, sobre lo que significa ser mujer y hombre, a partir del sexo las que generan las desigualdades. Como señala Lamas, "el feminismo estalló justamente a partir de la interpretación que se hacía de la diferencia entre los cuerpos de los hombres y los de las mujeres: puesto que tenían anatomías distintas, sus capacidades intelectuales y sus papeles sociales también habían de diferir; así, se aceptaba tranquilamente que las mujeres no tuvieran los mismos derechos ni las mismas opciones de vida que los hombres" (Lamas, 2002: 52). Todo ello dio lugar a la instauración de la categoría de género.

\section{Cuadro 1}

\section{Corrientes feministas}

\begin{tabular}{|c|l|}
\hline $\begin{array}{c}\text { Feminismo } \\
\text { liberal }\end{array}$ & $\begin{array}{l}\text { Conocido también como feminismo de la igualdad, orientado a } \\
\text { que la mujeres accedan a la plenitud de sus derechos civiles y } \\
\text { a la protección contra la discriminación por razón de su sexo; } \\
\text { promueven roles positivos para las niñas y las mujeres. Además, } \\
\text { procuran insertarse dentro del sistema a fin reformularlo a través } \\
\text { de leyes de igualdad } \\
\text { Entre algunas representantes están: Mary Wollstonecraft, Candy } \\
\text { Stanton, Simone de Beauvoir, entre otras. }\end{array}$ \\
\hline $\begin{array}{c}\text { Feminismo } \\
\text { radical }\end{array}$ & $\begin{array}{l}\text { Vinculado al feminismo de la diferencia. Se desconfía de todos } \\
\text { los valores y conceptos que se han desarrollado bajo un régimen } \\
\text { patriarcal, y promulgan la creación de valores femeninos y } \\
\text { centrados en las mujeres. } \\
\text { Entre algunas de sus exponentes están: Adrienne Rich, Hélène } \\
\text { Cixous, Luce Irigaray, Julia Kristeva, entre otras. }\end{array}$ \\
\hline Feminismo & $\begin{array}{l}\text { Entiende que la opresión de las mujeres es fruto tanto de la } \\
\text { dominación masculina como de la desigualdad económica, por } \\
\text { lo que la liberación de las mujeres se integra dentro de la lucha } \\
\text { de clases. } \\
\text { Representante: Michèle Barrett }\end{array}$ \\
\hline $\begin{array}{c}\text { Feminismo } \\
\text { psicoanalítico }\end{array}$ & $\begin{array}{l}\text { Estas feministas utilizan el concepto freudiano del inconsciente } \\
\text { para comprender y denunciar la opresión, al tiempo que rechazan } \\
\text { otros conceptos de Freud, como la envidia del pene. } \\
\text { Creen que el inconsciente puede servir para explicar cómo se } \\
\text { gestan las relaciones de poder entre hombres y mujeres, cómo se } \\
\text { internalizan, y por tanto, cómo podemos cambiarlas. } \\
\text { Creen que el patriarcado existe no sólo en la sociedad sino también } \\
\text { dentro de nosotras y nosotros, y que la identidad no es sólo el } \\
\text { producto de lo consciente sino también de lo inconsciente. } \\
\text { Representante: Juliet Mitchell }\end{array}$ \\
\hline
\end{tabular}




\begin{tabular}{|c|l|}
\hline $\begin{array}{c}\text { Feminismo } \\
\text { negro }\end{array}$ & $\begin{array}{l}\text { Las feministas negras consideran que las mujeres de color han } \\
\text { de definir su propia identidad, en vez de dejar esta misión a } \\
\text { las mujeres blancas o a los hombres negros, como ha ocurrido } \\
\text { históricamente. } \\
\text { Denuncian sobre todo el euro-centrismo que reina en los círculos } \\
\text { feministas más populares. } \\
\text { Representante: Angela Davis. }\end{array}$ \\
\hline $\begin{array}{c}\text { Feminismo del } \\
\text { tercer mundo }\end{array}$ & $\begin{array}{l}\text { Añade al feminismo negro la preocupación por estudiar la } \\
\text { situación de las mujeres dentro de países subdesarrollados o } \\
\text { en vías de desarrollo, que han sido colonizados por potencias } \\
\text { europeas y que a menudo son objeto de neocolonización. } \\
\text { Critican los parámetros de estudio del feminismo occidental y } \\
\text { buscan desarrollar sus propios paradigmas feministas, atendiendo } \\
\text { a las idiosincrasias propias de la situación post-colonial o neo- } \\
\text { colonial de la nación en que surge, así como a razones de raza, } \\
\text { etnia, religión, etc. } \\
\text { Representante: Chandra Talpade Mohanty. }\end{array}$ \\
\hline Ecofeminismo & $\begin{array}{l}\text { Advierte que la opresión de las mujeres y la destrucción de la } \\
\text { naturaleza son procesos asociados, fruto de la misma ideología } \\
\text { patriarcal. } \\
\text { Busca fórmulas de nueva relación y explotación de las tierras que } \\
\text { sean tanto ecológicas (desarrollo sostenible) como liberatorias } \\
\text { para las mujeres. } \\
\text { Representante: Vandana Shiva. }\end{array}$ \\
\hline
\end{tabular}

Fuente: Elaborado en base a Cuder (2002) y a la presentación de la catedrática Pilar Cuder en el modulo sobre Introducción al pensamiento feminista y a la historia de las mujeres del máster sobre Género, Identidad y Ciudadanía. Universidad de Huelva. Ciclo académico 2009/2010.

En otras palabras, las feministas cuestionaron que la inferioridad o subordinación que padece la mujer no es producto del sexo biológico (si no de aspectos de tipo sociocultural); es decir, no es posible sostener que la mujer por naturaleza es inferior al hombre, debido a la composición anatómica de su sexo/cuerpo y que consecuentemente se justifica que tanto hombres, como mujeres ocupen espacios distintos en la sociedad, ubicando a los hombres en una jerarquía mayor. Así la categoría género introducida por las feministas ha sido fundamental para explicar como la diferencia sexual-biológica, al introducir el filtro socio cultural, se traduce en desigualdades de tipo económicas, sociales y políticas entre mujeres y hombres.

El planteamiento feminista de la masculinidad y feminidad como construcción social condujo a la adopción del término género para distinguir en la construcción de la identidad, lo social de lo biológico. Como lo indica Linda MacDowell "una gran parte de las feministas contemporáneas han dedicado sus mayores esfuerzos a desmentir las aparentes inmutables diferencias basadas en el hecho biológico, a minar el pensamiento basado en la diferencia absoluta entre el 
hombre y la mujer, y a demostrar que la supuesta inferioridad femenina en materia de agilidad mental y fuerza física no responde a un fenómeno natural" (MacDowell, 1999: 30).

\section{La categoría género}

Podría decirse que una de las primeras nociones del concepto género, se identifica en el siglo XVII en los aportes desarrollados por el escritor francés Poulain de la Barre, que expone que la las desigualdades presentes entre hombres y mujeres están ligadas a factores culturales y no como producto de la naturaleza; partiendo de esa idea la pensadora y política Olympe de Gougesen emprende una lucha contra la supuesta inferioridad natural de la mujer. Por otra parte, la filósofa y escritora británica Mary Wollstonecraft critica el postulado de Jaen-Jacques Rousseau que considera naturales los roles asignados a las mujeres.

En el siglo XIX el concepto se estuvo alimentando del movimiento sufragista por el voto de las mujeres. En el siglo XX los aportes de la filosofa Simone de Beauvoir y la antropóloga Margaret Mead, fueron determinantes para el surgimiento de género como categoría de análisis; así por ejemplo Beauvoir en su obra Segundo Sexo afirma que "Una no nace, sino que se hace mujer", afirmación que se encuentra interiorizada en la categoría género.

El concepto de género está en constante evolución, sin embargo, el rasgo común en todas las definiciones es ese orden sociocultural que define lo masculino, femenino y otros géneros de la especie humana. el cuadro 2 , expone un recorrido de la evolución del concepto a finales del siglo XX

De las definiciones del cuadro 2 se deriva que el género se refiere a las características socialmente construidas sobre la base de la diferencia sexualbiológica. Por lo tanto, sexo y género no son igualables o sinónimos. El sexo se entiende como "las características anatómicas de los cuerpos, incluida la genitalidad, así como las características morfológicas del aparato reproductor y aspectos tales como las diferencias hormonales y cromosómatica." (Martín, 2006: 38). Así podría decirse que el sexo tiene que ver con la naturaleza, está determinado biológicamente, dado por los genes y se refiere a la diferencias biológicas entre hombre y mujer; en tanto que el género, tiene que ver con la cultura, es culturalmente modificable, adquirido mediante procesos de socialización y tiene que ver con las diferencias sociales entre hombres y mujeres.

3. Este apartado sistematiza y resume, en parte, los principales aportes expuestos en capítulo 1 del libro de Martín Casares los cuales se complementas con otras obras que se citan. 


\section{Cuadro 2}

Definiciones de género

\begin{tabular}{|c|c|}
\hline $\begin{array}{c}\text { Investigaciones } \\
\text { en la década } \\
\text { de los } 80\end{array}$ & $\begin{array}{l}\text { Por género se entendía una creación exclusivamente social: } \\
\text { lo que las representaciones colectivas interpretaban como } \\
\text { ser socialmente un hombre o una mujer, es decir, el conjunto } \\
\text { de atributos que se asocian a cada categoría biológica en una } \\
\text { determinada cultura; en definitiva la construcción cultural de lo } \\
\text { femenino y lo masculino. }\end{array}$ \\
\hline $\begin{array}{c}\text { Joan Scott } \\
(1986) . \\
\text { Historiadora }\end{array}$ & $\begin{array}{l}\text { Esta historiadora concibe el género como un todo integrado } \\
\text { por dos partes: a) un elemento constitutivo de las relaciones } \\
\text { basadas en las diferencias que distinguen los sexos y b) una forma } \\
\text { primaria de las relaciones significantes de poder entre los sexos. } \\
\text { Al mismo tiempo su definición contempla cuatro elementos } \\
\text { interrelacionados: los símbolos, conceptos normativos, las } \\
\text { instituciones y la identidad subjetiva. }\end{array}$ \\
\hline $\begin{array}{l}\text { Lourdes } \\
\text { Banería (1987). } \\
\text { Catedrática de } \\
\text { la Universidad } \\
\text { de Cornell } \\
\quad \text { (EEUU) }\end{array}$ & $\begin{array}{l}\text { Lo define como el conjunto de creencias, rasgos personales, } \\
\text { actitudes, sentimientos, valores, conductas y actividades que } \\
\text { diferencian a hombres y mujeres a través de un proceso de } \\
\text { construcción social que tiene varias características: 1) es un } \\
\text { proceso que se desarrolla a diferentes niveles como el mercado, } \\
\text { estado y otros; y } 2 \text { ) supone la jerarquización de los rasgos y } \\
\text { actividades, de tal modo que a lo que se define como masculino } \\
\text { es a lo que se otorga mayor valor. }\end{array}$ \\
\hline $\begin{array}{l}\text { Dolors Comas } \\
\text { (1995). } \\
\text { Antropóloga } \\
\text { Social }\end{array}$ & $\begin{array}{l}\text { La noción de género se refiere al conjunto de contenidos, o } \\
\text { de significados, que cada sociedad atribuye a las diferencias } \\
\text { sexuales. Se trata, por tanto, de una construcción social que } \\
\text { expresa la conceptualización que hace cada sociedad de lo } \\
\text { masculino y lo femenino (o de otros géneros posibles) en relación } \\
\text { a las categoría de hombre y de mujer como seres sexuados y, por } \\
\text { tanto, biológicamente diferenciados. }\end{array}$ \\
\hline
\end{tabular}

Fuente: Martín, 2006.

Cabe señalar que las definiciones mayoritariamente reconocidas de género plantean una concepción binaria o noción dual (masculino y femenino) y que tiene su base en el dualismo biológico (hombre y mujer). Al respecto Butler plantea:

"Si por el momento damos por sentada la estabilidad del sexo binario, no es evidente que la construcción de "hombres" dará como resultado únicamente cuerpos masculinos o que las "mujeres" interpreten sólo cuerpos femeninos. Además, aun cuando los sexos parezcan ser claramente binarios en su morfología y constitución (lo que tendrá que ponerse en duda), no hay ningún motivo para creer que también los géneros seguirán siendo sólo dos. La suposición de un sistema binario de géneros mantiene de manera implícita la idea de una relación mimética entre género y sexo, en la cual el género refleja al sexo o, de lo contrario, está limitado por él" (Butler, 2001: 39). 
Butler está poniendo en evidencia que la categoría género no ha considerado a otras prácticas sexuales, que conducen a distintas construcciones genéricas y plantea la posibilidad de que el sexo sea tan culturalmente construido como el género, por lo tanto no podría definirse el género como una interpretación cultural del sexo.

Es necesario agregar que la posición binaria del sexo (hombre/mujer) excluye a las personas hermafroditas, que al considerarlas se desestabiliza la noción hombre/mujer como tradicionalmente se conoce, plantea la posibilidad de más de dos sexos. Por otra parte, Marta Lamas lanza al debate la importancia del inconsciente en la formación de la subjetividad y sexualidad, lo que estaría indicando que tanto la cultura, como el inconsciente son factores importantes para la construcción de la identidad de las personas (Lamas, 2002).

En definitiva, la idea es multiplicar el género más allá de la noción masculina y femenina a fin de que se puedan considerar otras formas de construcciones socioidentitarias como la andrógina, transgénero, bisexual, lésbica y homosexual que permitan romper con la rigidez de la normatividad heterosexual y/o de los estereotipos de género dominantes en nuestra sociedad.

A fin de superar el debate de las concepciones binarias, actualmente se tiende a definir el género "como una categoría de análisis científico que se refiere a las cualidades culturales y sociales que se asocian simbólicamente a las personas según las formas de concebir las identidades genéricas en cada sociedad". En esa misma línea, Martín utiliza la definición de género como una "categoría analítica abstracta aplicable a la construcción de la masculinidad, la femenidad, la andrógina u otras categorías socio-biológicas definidas en cada sociedad que permite estudiar los roles, estereotipos, relaciones de poder y estratificaciones establecidas"(Martín, 2006: 48).

Dicho concepto supone que el uso de esta categoría para el estudio de las construcciones socioculturales de las identidades y relaciones de género no se limita al género masculino y femenino, sino que tiene sus variantes según el contexto social, étnico, geográfico, etc. La definición que plantea Martín permite sacar de la marginalidad otras prácticas y construcciones identitarias, así el transexualismo, el androcentrismo, la homosexualidad, el lesbianismo y la bisexualidad son campos de análisis o de estudio de la perspectiva de género.

Lamas (2002: 35-36) plantea que en la categoría género se articulan tres instancias básicas (la cuales considero que son vigentes en la definición desarrollada por Martín). La primera, la asignación de género, la cual se realiza a partir de la apariencia externa de los genitales al momento del nacimiento de una persona. Así las personas cuya apariencia genital es el pene se asigna el género masculino y a las con vulva corresponde el femenino, con lo cual en cierta medida, desde el nacimiento, se definen las oportunidades que tendrán estas personas en la sociedad. 
La segunda, la identidad de género, proceso psicosocial por medio del cual las personas se identifica con el género asignado, es el proceso de reconocerse como hombre/masculino y como mujer/femenina de acuerdo a lo que la sociedad establece como tal; sin embargo, Martín, agrega que la identidad no es estable y está vinculada con las prácticas sexuales de las personas y la evolución de sus percepciones. A esto se agregaría que en la medida que no se reconozcan y se estigmaticen otras identidades genéricas, el desarrollo psicológico de las personas (especialmente en la niñez y adolescencia) puede verse mermado.

La tercera es el rol de género, se refiere al conjunto de normas, deberes, obligaciones que la sociedad otorga a las personas sobre el comportamiento masculino o femenino. Así se asocia a las mujeres o a los hombres con determinadas actividades o comportamientos. Por ejemplo, entre algunos roles tradicionales asignados a las mujeres se destacan: fidelidad, debilidad, virginidad, docilidad, encargada del cuido del hogar-familia, de la casa o los espacios privados. En tanto que los hombres se cataloga de: aventurero, fuerte, experimentado sexualmente, proveedor de la familia y participación de los públicos

Adicional a las instancias planteadas por Lamas, Joan Scott platea que el género integra cuatro elementos interrelacionados, los cuales se exponen en la Figura 1 , para Scott el género se constituye cuando hay una interrelación entre los símbolos y mitos culturalmente disponibles, la normatividad que da sentido a los mismos, las instituciones que los refuerzan e antevienen y la identidad subjetiva de cada persona o grupo.

Figura 1

Elementos que integran el género

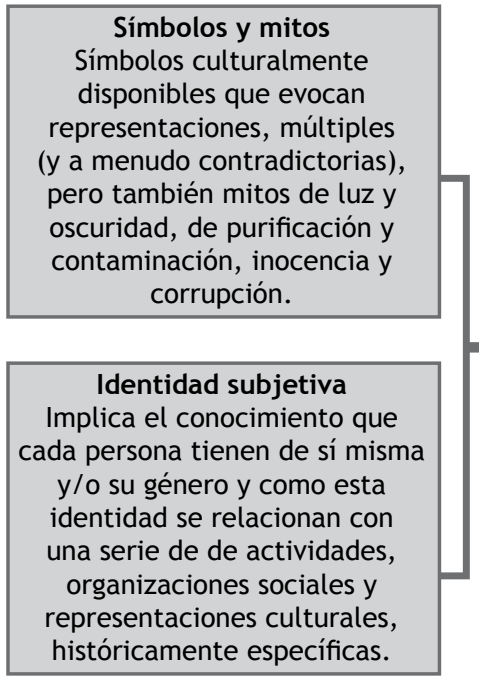

Conceptos normativos Conceptos normativos que manifiestan las interpretaciones de los significados de los símbolos, en un intento de limitar y contener sus posibilidades metafóricas. Esos conceptos se expresan en doctrinas religiosas, educativas, científicas, legales y políticas, que afirman categórica y unívocamente el significado de los sexos y géneros

Instituciones y organizaciones sociales

Instituciones y organizaciones sociales de relaciones de género como el sistema de parentesco, la familia, el mercado de trabajo, las instituciones educativas y la política

Fuente: Scott, 1990 
Martín expone otros conceptos relacionados a la categoría género, como el de relaciones de género, estratificación de género, estereotipos de género y transgénero. Las relaciones de género "son las relaciones de dominación, conflicto o igualdad que se establecen entre los géneros en una sociedad determinada". La estratificación "se refiere a las desigualdades entre hombres y mujeres, reflejadas en la jerarquización social y la dominación masculina existente en la mayoría de las sociedades". Los estereotipos "son construcciones sociales que forman parte del mundo simbólico y constituyen una de las armas más eficaces contra la equiparación de las personas". Y transgénero, se refiere a "individuos, comportamientos y grupos que presentan divergencias con los roles de género duales (masculino/femenino), ya que traspasan las fronteras de identidad genérica comúnmente asignada"; se identifican dentro de estos individuos o grupos a las personas andróginas y transexuales (Martín, 2006: 5053).

Para finalizar este apartado, es preciso exponer dos términos que son fundamentales para los estudios de género: perspectiva de género y análisis de género. A partir de los aportes desarrollados por Marcela Lagarde en su libro Género y Feminismo, interpreto la perspectiva de género como aquella que busca analizar y comprender las expectativas, oportunidades, relaciones sociales y de poder entre los géneros, las cuales tienen sus repercusiones en la vida social, sexual, política, cultural y económica de las personas. Así mismo incluye el análisis del entramado institucional y legal en la relaciones de género y sus vinculaciones con otras categorías sociales como etnia, religión, clase, condición de origen, ubicación geográfica, educación, edad y preferencia sexual.

El análisis de género implica el estudio de las formas de organización y funcionamiento de las sociedades y analiza las relaciones sociales desde la perspectiva de género; desde la visión binaria, estas relaciones se desarrollan entre mujer a mujer, de hombre a hombre, de hombre a mujer y viceversa considerando los roles de géneros y variables como trabajo, acceso a recursos $\mathrm{y}$ tomas de decisiones. ${ }^{4}$

\section{El aporte de la antropología al género}

El feminismo y el desarrollo de la categoría género han permitido la visibilidad de las mujeres en los estudios antropológicos y etnográficos, así como también la consideración de las relaciones sociales y de poder entre los géneros (especialmente entre el género masculino y femenino) en los mismos. No obstante, como se planteó al inicio, los aportes antropológicos/etnográficos

4. GPE/OIT. Proyecto Género, Pobreza y Empleo (GPE) para América Latina http://white.oit.org.pe/gpe// pagina.php?objetivo=22\#1 Consultado el 1 de febrero 2010. 
han sido fundamentales para la lucha política del movimiento feminista, la desconstrucción del determinismo biológico que ubica a las mujeres en una escala de inferioridad y para cuestionar el carácter universal de muchos de los roles y estereotipos de género de las sociedades occidentales asignados a hombres y mujeres, considerados propios de su naturaleza humana o de su sexo.

En ese sentido, este apartado expone brevemente el recorrido que hace Martín sobre los aportes de los estudios antropológicos, los cuales he organizado en función de cuestionar o desmitificar los roles y estereotipos dominantes en nuestra sociedad.

La sociedad occidental y la organización patriarcal de la misma, establecen una serie de estereotipos que reproduce en el imaginario social situaciones de desigualdad e inferioridad entre los géneros. Así entre algunos estereotipos y/o roles de género de las mujeres se destacan: sumisas, subordinadas, inestables emocionalmente, sentimentales, dependientes, frívolas, responsables del hogar, vírgenes y fieles, etc.; en tanto que los hombres son dominantes, estables emocionalmente, independientes, valientes, agresivos, sexualmente experimentados, aventureros, independientes, dueños de la palabra, racionales, etc.; para ambos se establece como valores universales la heterosexualidad obligatoria y matrimonio heterosexual. Con los aportes antropológicos (articulados a otras disciplinas) ha sido posible entender que no hay una sólo forma de construcción masculina y femenina, que ésta es culturalmente modificable.

Retomado el recorrido que hace Martín en la recuperación de los aportes de antropólogas pioneras, se destaca las etnografías realizadas por Phyllis Kaberry (1910-1977) con los aborígenes australianos, en la que demostró que no en todas las sociedades las mujeres están subordinadas o sometidas a la autoridad masculina, pues observó que en las sociedades de cazadores-recolectores se evidencia una relativa igualdad entre mujeres y hombres, las mujeres (como esposas) tiene control sobre el uso de la tierra en relación a la cosecha que ellas cultivan, así como también poseían propiedad de la tierra en función de la sucesión y la residencia.

Desde una lectura antropológica de El Segundo Sexo de la filosofa Simone de Beauvoir (1908-1986), se sustrae que la mujer al determinarse o definirse con respecto al hombre (y no a la inversa o consigo misma) ha generado consecuencias graves en la misma. Plantea que la evolución del pensamiento occidental en la construcción social de la feminidad ha estado marcada por la idea de los filósofos griegos que consideran a las mujeres como sujetos pasivos en la sociedad y en la reproducción. Además, que la subordinación de las mujeres no puede explicarse en función de la biología, aspectos como el social, económico y psicológico son fundamentales para entenderla. 
En cuanto al matrimonio, plantea que es una institución que permite a los hombres el acceso a la dignidad adulta y no necesariamente es un vínculo entre hombres y mujeres, sino entre los mismos por medio de las mujeres. Respecto a la virginidad femenina, se ha establecido como un valor social vinculado a la necesidad de los hombres de evitar el riesgo de transferir los bienes a un heredero ilegítimo y para asegurar el linaje por línea paterna; a esto agregaría que la virginidad también constituye una forma de control del placer y la sexualidad femenina, que consecuentemente repercute en el control del hombre sobre la mujer.

En relación a los roles de género, por medio de las etnografías realizadas por la antropóloga Margaret Mead (1901-1978) en Samoa y Nueva Guinea se deriva que los roles de género cambian de una sociedad a otra y que difieren en cada contexto histórico. Mead contribuyó considerablemente al desarrollo de la categoría género al separar la cualidades biológicas de los humanos de la aquellas que son culturales.

En esa misma línea, Martín, expone que etnografías recientes plantean una multiplicidad de roles masculinos y femeninos que difieren de la concepción occidental, como es rol transgenérico (más evidente en su vestimenta y voto de castidad), en uno de los grupos religiosos más importantes de nuestra sociedad; el cual no corresponde con el estereotipo de género masculino occidental. Entre los indígenas Piegan de Canadá, existía un tipo de mujer que presentaba características del estereotipo de género masculino, conocidas como "mujer con corazón de hombre". En la India los Hijras constituye un grupo (religioso) transgénero, hombres que tienen roles rituales femeninos, sin los prejuicios que se tienen en occidente. Para los Inuit (ubicados en Canadá, Alaska y Groenladia) la identidad de género está en función de su alma-nombre y no del sexo biológico, pero cuando llegan al matrimonio realizan actividades y trabajos de su sexo. En los Sambia de Nueva Guinea tener genitales masculino no significa ser hombre, la masculinidad se construye por medio de la producción y recepción de semen, lo que supone que la homosexualidad está institucionalizada y la feminidad es innata

Al igual que los Sambia, los estudios sobre los Two Espirit o Berdaches (Norte América), estarían desmitificando como valor natural e universal en todas las sociedades la heterosexualidad obligatoria. Los Berdaches (con sus variantes) adoptan las vestimentas, maneras y función cultural del sexo opuesto, también en algunos casos no implicaba la renuncia a ciertas actividades y vestimenta asignadas a su sexo; si bien la mayoría de estos elegían parejas sexuales de su propio sexo biológico, algunos eran célibes y otros en sus relaciones sexuales seguían siendo heterosexuales; adicionalmente, gozaban de respeto y cierta reverencia de la comunidad o pueblo (Herrero, 2001: 118-119 y Mondimore, 1998: 29-31). Los Mohave (indios que vivían en California, Estados Unidos) 
realizaban ceremonias para hombres o mujeres que adoptaban roles diferentes a su sexo a fin de legitimar el cambio de posición, podían contraer matrimonio y ejercer la maternidad según el caso. (Martín y Voorhies, 1978: 91-92).

En el pueblo amerindio Navajo (Estados Unidos) se identifican personas a las que se le llama nadles, cuyo aspecto sexual difiere del hombre y mujer (pero también hay nadles cuyos genitales son masculinos o femeninos), realizan funciones y tareas tanto masculinas como femeninas (excepto la guerra y caza); gozan de cierta ventajas en aspectos económicos, en la disposición de la propiedad privada de sus parientes y realizan la función de mediadores de las disputas entre hombres y mujeres; pueden casarse tanto con hombres como con mujeres, pero los auténticos nadles por lo general no se casan (Martín y Voorhies, 1978: 87-88). La cultura navajo difiere en la noción dual de sexo y género con respecto a nuestra cultura occidental, para los navajos las personas se estarían clasificando en nadle, masculina y femenina y nos están planteando la existencia de tres sexos.

También, Martín expone, que la antropología ha documentado matrimonios entre mujeres en grupos étnicos subsahariano, donde el liderazgo femenino es frecuente. También, en los grupos como los Nuer, Lozi y Zulú en África se han encontrado matrimonios de este tipo que siguen procedimientos ceremoniales similares al matrimonio heterosexual e incluso tienen acceso a la procreación ya que una de la pareja toma un pariente o vecino hombre para inseminar a la esposa.

En los Azande del África oriental, los jóvenes guerreros de la corte, podían contraer matrimonio con otros hombres jóvenes, siguiendo las mismas costumbres de los matrimonios heterosexuales; también, una vez casado dos hombres, uno de ellos podía casarse nuevamente (cumpliendo ciertos requisitos de tipo económico) con una mujer y el otro volvía a desarrollar sus funciones de guerrero (Martín y Voorhies, 1978: 97-98).

Por último, la antropóloga Sherry Ortner desarrolla la idea que el motivo que las mujeres estén simbólicamente asociadas a la naturaleza (por su fisiología y capacidad reproductiva) y los hombres a la cultura (dado que el hombre carece de capacidades naturales creativas, éste crea a través de expresiones culturales) ha conducido a una subordinación de las mujeres con respecto a los hombres; como consecuencia de que la naturaleza está subordinada a la cultura. No obstante, no en todas las sociedades se establece la relación jerárquica cultura/naturaleza y hombre /mujer, como lo evidencia las etnologías sobre los Kaulong de Nueva Bretaña y Gimi de Papua Nueva Guinea.

La importancia de conocer estos casos de etnografías de culturas o sociedades distintas a la occidental, nos permite comprender que los seres humanos 
tenemos distintas formas de entender e interpretar la sexualidad, roles y relaciones de género; por lo tanto, las relaciones de desigualdad que se presentan entre hombres y mujeres y otros géneros no son universales y no se pueden justificar como naturales y son culturalmente modificables. Basta ver en la misma sociedad occidental para enterarnos que la construcción de los géneros es diferente de una cultura a otra. Es necesario revisar nuestras identidades de género, aprender de las culturas que nos permitan una sociedad más igualitaria e incluyente para toda la humanidad.

\section{Consideraciones finales}

A manera de consideración final, destaco que la categoría género ha constituido un aporte valioso del feminismo a las ciencias y a la sociedad, en la búsqueda de igualdad entre hombres y mujeres, a la redefinición de las políticas públicas y a tomar en cuentas que éstas no son neutrales en cuanto a los impactos sobre las mujeres y los hombres.

La categoría género no es sinónimo de mujer, ni de feminismo, ni estudios relativos únicamente de la mujer; constituye una categoría en constante evolución, así como de análisis aplicado a todos los campos de la ciencias, también a las construcciones identitarias de género más allá de la masculina y femenina, en las que se interrelaciones una serie de elementos e instancias como las planteadas el desarrollo de estos apuntes. Además, como destaca Martín "El mero hecho de ser conscientes de que la identidad se construye conforme a criterios sociales, incluso aunque la persona opte por seguir los cánones mayoritarios, supone un avance en el crecimiento personal e implica un menor grado de discriminación hacia otras personas que decidan revelarse contra el sistema de género imperante" (Martín, 2006: 44).

Con el breve recorrido de aportes antropológicos se afirma que los estereotipos y roles de género presentes en el imaginario colectivo de la sociedad occidental y/o euroamericana no son universales, que la feminidad y masculinidad varia de una sociedad a otra, que la cultura o los símbolos culturales en cada sociedad juegan un papel importante en la construcción de cada género. No obstante, cada vez se está reconociendo la importancia de la realidad corpórea y psíquica de las personas en la construcción de la identidad de las personas.

La categoría género, aparte de explicar la construcción de los géneros y las relaciones entre los mismos, busca y propone reconstruir las identidades genéricas sobre la base de la inclusión social, y constituye una herramienta fundamental para evaluar el desempeño de las políticas públicas en la consecución de igualdad de oportunidades para todos los géneros. 


\section{Bibliografía}

Butler, Judith (2001) El género en disputa: el feminismo y la subversión de la identidad. Editorial Paidos Mexicana.

Cuder, Pilar (2002) Tiempos de Feminismos. En Introducción a los Estudios de la Mujer: una mirada desde las ciencias sociales. Moreno, Emilia y Villegas, Sonia, Eds. Universidad de Huelva.

GPE/OIT. Proyecto Género, Pobreza y Empleo (GPE) para América Latina http:// white.oit.org.pe/gpe//pagina.php?objetivo=22\#1 Consultado el 1 de febrero 2010.

Herrero, Juan (2001) La sociedad gay: una invisible minoría. Foca ediciones. España

Lagarde, Marcela (1996), Género y feminismo: desarrollo humano y democracia. Cuadernos Inacabados No, 25, España.

Lamas, Marta (2002) Cuerpo: dieferencia sexual género. Taurus Pensamiento. México.

Martín Casares, Aurelia (2006) Antropología del género: culturas, mitos y estereotipos sexuales, Ediciones Cátedra, Universidad de Valencia.

Martin, Kay, M. y Voorhies, Barbara (1978): La mujer: un enfoque antropológico. Editorial Anagrama, Barcelona.

McDowell, Linda (1999) Género, Identidad y lugar, Ediciones Cátedra, Universidad de Valencia.

Mondimore, Francis Mark (1998) Una historia natural de la homosexualidad. Paidos Contextos. España.

Mujeres en Red: el periódico feminista. Qué es el feminsmo. http://www. mujeresenred.net/spip.php?article1308 Consultado el 27 de enero de 2010.

Scott, Joan (1990). El género: una categoría útil para el análisis histórico. En Historia y género: las mujeres en la Europa moderna y contemporánea, James y Amelang y Mary Nash (eds.), Edicions Alfons el Magnanim, Institució Valencina d Estudis i Investigació. 